\title{
Duplication cyst of the esophagus: A rare congenital cause for vomiting and respiratory distress
}

\author{
Saeed Al Hindi, Khaled Nazzal, Husain Al Aradi, Mohamed Mubarak*
}

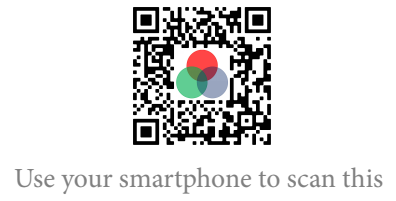

QR code and download this article

\begin{abstract}
A duplication cyst of the esophagus is the $2^{\text {nd }}$ most common congenital anomaly of the gastrointestinal tract. Although these benign cystic masses can be picked up routinely on a chest X-ray, patients may experience symptoms such as stridor or dysphagia corresponding to lesions within the neck or mediastinum. We present a rare case of a duplication cyst of esophagus in a 2-weekold female baby, which was surgically excised. Our aim in this case report is to raise awareness of this congenital disorder; especially when differential diagnoses such as acute respiratory distress syndrome (ARDS), failure to thrive, asthma, pneumonia, neuromuscular disorders and suspected foreign body inhalation have been ruled out in the pediatric patient.
\end{abstract}

Key words: Duplication Cyst, Esophageal Cyst, Congenital Cyst, Dysphagia, Respiratory Distress

\section{BACKGROUND}

Duplications occurs as a result of a defect in the normal vacuolization process of the esophagus, which normally occurs in the sixth gestational week ${ }^{1}$. patients may experience symptoms such as stridor or dysphagia corresponding to lesions within the neck or mediastinum ${ }^{2}$. The majority of oesophageal duplications occur distally and on the right side, as in our case. Macroscopically, there are three forms of esophageal duplications which exist: (1) cystic (2) tubular and (3) diverticular forms ${ }^{3}$. We therefore present a case of a 2-week-old female baby who was diagnosed with a duplication cyst of the esophagus. In epidemiology, this diagnosis is prevalent in $22 \%$ of patients before the age of two.

\section{CASE PRESENTATION}

A 2-week-old female baby presented with recurrent non-bilious vomiting since birth associated with respiratory distress. She was otherwise well with no feeding problems. On clinical examination, her abdomen was soft, non-tender with no obvious palpable masses to suggest organomegaly. Upon auscultation of the lung fields there was a bilateral inspiratory wheeze. A clinical assessment of the patient showed a temperature of $36.8^{\circ} \mathrm{C}$, a heart rate of 120 beats per minute, a respiratory rate of 24 breaths per minute and a blood pressure reading of $106 / 72 \mathrm{mmHg}$.

Preliminary blood investigations were ordered including a full blood count, inflammatory markers, liver function and renal function tests which were unremarkable. In view of the patient's respiratory distress, a chest X-ray was ordered initially and showed a clear right cystic border within the mediastinum with some obscuring of the right cardiac border. On magnetic resonance imaging (MRI) there was confirmation of a right mediastinal giant cyst (Figure 1) in both the coronal and sagittal plane. The cyst measured as $4.9 \times 8.0 \mathrm{~cm}$ corresponding to maximal horizontal and vertical diameter respectively (Figure 2). Surgery was therefore planned to excise the cyst.

The patient was admitted for surgery under general anesthesia with endotracheal intubation. She was placed in the full left lateral decubitus position and a nasogastric tube was inserted. A right thoracotomy was performed and with observation of the cyst it was found to be detached and separate from the esophagus. A decision was made to excise the cyst with complete removal from the mediastinum. To avoid complications of perforation to the esophagus a fiberoptic bronchoscope was inserted and the right giant cyst was removed. Histology of the specimen revealed esophageal tissue consistent with duplication cyst of the esophagus. (Figure 3) The patient did well postoperatively and was discharged home 5 days after surgery. A follow-up of the patient after 6 months revealed no further episodes of recurrent vomiting or respiratory distress, with the patient making a prompt recovery. 


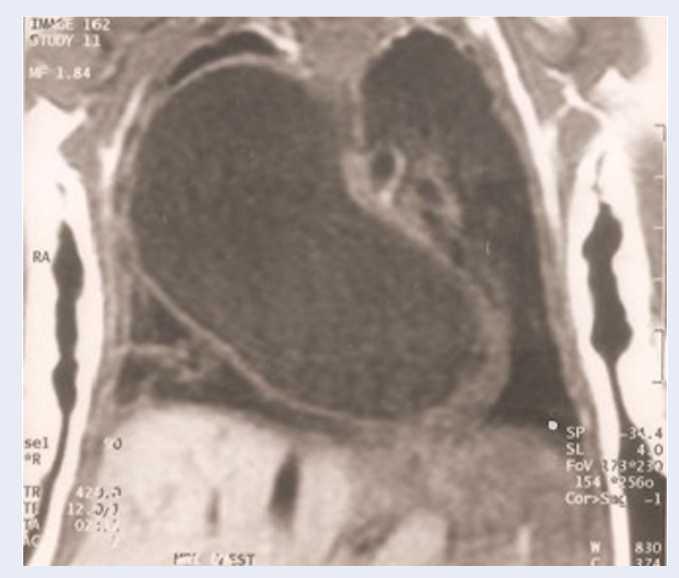

Figure 1: MRI Scan showing right mediastinal giant cyst.

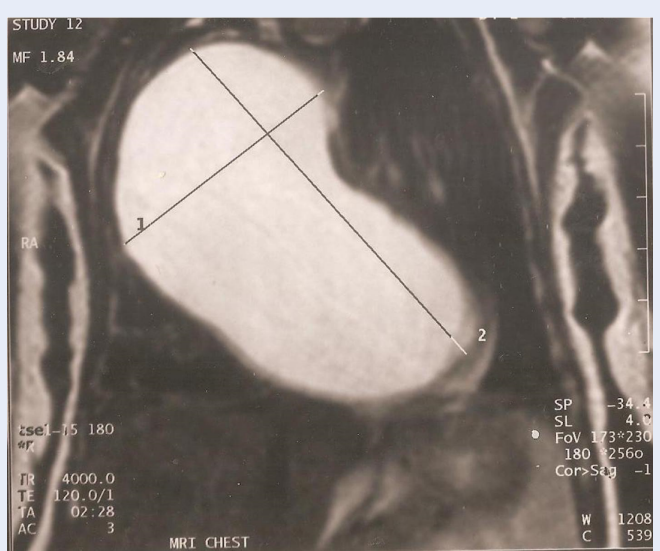

Figure 2: Cyst measuring as $4.9 \times 8.0 \mathrm{~cm}$ corresponding to maximal horizontal and vertical diameter respectively.

\section{DISCUSSION}

Duplication cyst of the esophagus is the $2^{\text {nd }}$ most common congenital anomaly of the gastrointestinal tract, following lesions of the ileum which account for $10-15 \%$ of cases ${ }^{4}$. These are usually benign cystic masses that are located within the neck or mediastinum and can be associated with other congenital anomalies such as esophageal atresia, tracheoesophageal fistulas and abnormalities such as spinal scoliosis ${ }^{5}$. As duplication cysts originate from the primitive foregut, they contain esophageal tissue and surrounding muscle.

The symptoms experienced by a patient depends upon the location of duplication cysts; although these can be picked up asymptomatically on routine chest $\mathrm{x}$-ray. A superior lesion within the neck is responsible for dyspnea or stridor, mainly due to its compressive effect on the trachea. A mediastinal lesion will hence cause dysphagia due to its proximity or involvement with the esophagus.

A literature search was conducted using PubMed and Google Scholar Databases with keywords "Duplication Esophageal Cyst" as our primary search criteria. After an evaluation of abstracts, we found a total of 80 case reports alluding to management of patients with this diagnosis; the majority of which were pediatric cases (55\%). To our surprise, there were several non-congenital variations in presentation with or alongside duplication cyst of the esophagus. These included retrosternal chest pain and vomiting ${ }^{6}$, stromal tumor $^{7}$, esophageal web ${ }^{8}$, cystic bronchiectasis ${ }^{9}$ and left lung collapse with hypoperfusion ${ }^{10}$.

The main approach for treatment involves complete excision of the duplication cyst, due to the possibility of malignancy which has been reported in the literature. The surgical options include axillary tho- 


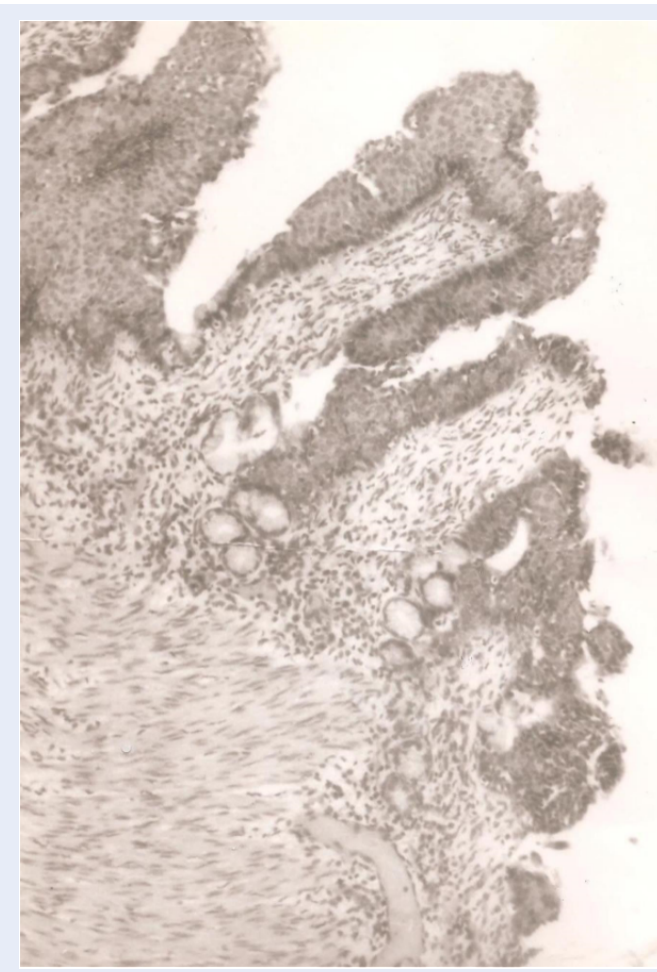

Figure 3: Histology of the specimen revealed esophageal tissue consistent with duplication cyst of the esophagus.

racotomy, median sternotomy or minimally invasive thoracoscopic approach for mediastinal lesions. In our case, we felt the best approach was a right thoracotomy to gain access to the giant cyst as our preoperative images show (Figures 1 and 2).

\section{CONCLUSION}

In conclusion, the decision to perform a thoracotomy or use minimally invasive thorascopy depends upon numerous factors including size, location, proximity to surrounding structures as well as cost, availability and personal preference of the surgeon. We intend to raise awareness of this rare diagnosis through this case report.

\section{CONSENT}

Verbal consent has been obtained from the patient for publication of this Case Report and any accompanying images. Complete anonymity was ensured during the process of writing the report.

\section{CONFLICT OF INTEREST STATEMENT}

The authors have no conflict of interest.

\section{AUTHOR CONTRIBUTIONS}

SA and HA were the patient's attending physicians and responsible for manuscript revision and final approval. KN and MM were responsible for data collection, writing and revising the manuscript. All authors approved the final manuscript.

\section{REFERENCES}

1. Shew SB, Holcomb GWI. Alimentary tract duplications. Pediatric Surgery. 2005;4:543-552.

2. Gupta B, Meher R, Raj A, Agarwal S. Duplication cyst of the oesophagus: a case report. Journal of Paediatrics and Child Health. 2010;46:134-135. PMID: 20415993. Available from: https://doi.org/10.1111/j.1440-1754.2010.01698.x.

3. Nazem M, Amouee AB, Eidy M, Khan IA, Javed HA. Duplication of cervical oesophagus: A case report and review of literatures. Afr J Pediatr Surg. 2010;7:203-205. PMID: 20859033. Available from: https://doi.org/10.4103/0189-6725.70429.

4. Whitaker JA, Defenbough LD, Cooke AR. Esophageal duplication cyst. Am J Gastroenterol. 1980;73:329-332.

5. Sethi GK, Marsden J, Johnson D. Duplication cyst of the esophagus. South Med J. 1974;67:616-618. PMID: 4823366. Available from: https://doi.org/10.1097/00007611-19740500000025 .

6. Singh AK, Reddy L, Khan A, Kamath CP, Das V. Adult with recurrent chest pain and vomiting. Diagnosis: Esophageal duplication cyst. Chest. 2013;144(1):341-346. PMID: 23880684. Available from: https://doi.org/10.1378/chest.12-0701.

7. Mansard MJ, Rao U, Rebala P, Rao GV, Reddy DN. Esophageal duplication cyst masquerading as a stromal tumour in an adult. Indian J Surg. 2011;73(6):441-443. PMID: 23204704. Available from: https://doi.org/10.1007/s12262-011-0250-5. 
8. Snyder CL, Bickler SW, Gittes GK, Ramachandran V, Aschraft KW. Esophageal duplication cyst with esophageal web and tracheoesophageal fistula. J Pediatr Surg. 1996;31(7):968969. Available from: https://doi.org/10.1016/S0022-3468(96) 90424-8.

9. Kitano Y, Iwanaka T, Tsuchida Y, Oka T. Esophageal duplication cyst associated with pulmonary cystic malformations. J
Pediatr Surg. 1995;30(12):1724-1727. Available from: https: //doi.org/10.1016/0022-3468(95)90465-4.

10. Holemans JA, Rankin SC. Case report: oesophageal duplication cyst causing left lung collapse and hypoperfusion. $\mathrm{Br} \mathrm{K}$ Radiol. 1995;68(805):82-84. PMID: 7881889. Available from: https://doi.org/10.1259/0007-1285-68-805-82. 